\title{
Cephalometric changes in nasopharyngeal area after anterior maxillary segmental distraction versus Le Fort I osteotomy in patients with cleft lip and palate
}

\author{
Soodeh Tahmasbi ${ }^{1}$, Abdolreza Jamilian ${ }^{2}$, Rahman Showkatbakhsh ${ }^{1}$, \\ Fereydoun Pourdanesh ${ }^{3}$, Mohammad Behnaz ${ }^{1}$
}

Correspondence: Dr. Mohammad Behnaz Email: behnaz1357@yahoo.com

\author{
'Department of Orthodontics, School of Dentistry, \\ Shahid Beheshti University of Medical Sciences, \\ Tehran, Iran, \\ ${ }^{2}$ Department of Orthodontics, School of Dentistry, \\ Islamic Azad University, Tehran, Iran, \\ ${ }^{3}$ Department of Oral and Maxillofacial Surgery, School \\ of Dentistry, Shahid Beheshti University of Medical \\ Sciences, Tehran, Iran
}

\section{ABSTRACT}

Objective: The present study was designed to compare the effects of two surgical methods, anterior maxillary segmental distraction (AMSD) versus conventional Le Fort I osteotomy, on cephalometric changes of velopharyngeal area of patients with cleft lip and palate. Materials and Methods: This study was conducted on 20 CLP in two groups. The first group had classic Le Fort I maxillary advancement and the second group had AMSD with a modified hyrax as an intraoral tooth-borne distractor. In the second group, 1 week after the surgery, activation of hyrax screw was started with the rate of 2 times a day for about 10 days. Initial and final lateral cephalograms were traced and analyzed by OrthoSurgerX software. Results: The changes in variables evaluating velopharyngeal status showed a significant difference between the two groups. In Group A (conventional), the mean of nasopharyngeal area and Nasopharynx floor length showed a significant increase $(P<0.05)$ after the surgery, while in Group B (DO), the trend of changes was vice-versa. The changes in SNA, overjet, and soft-tissue convexity were similar in both groups. Conclusion: AMSD can improve facial profile, almost similar to the conventional Le Fort I advancement, while there is a significant decrease in nasopharyngeal; hereby there is no increase in the velopharyngeal sphincter.

Key words: Anterior maxillary segmental distraction, cleft lip and palate, velopharyngeal area

\section{INTRODUCTION}

Most of the Patients with cleft lip and palate suffer from maxillary hypoplasia mostly due to soft-tissue scarring from lip and palate repair. ${ }^{[1]}$ This problem should be addressed by orthopedic advancement of the maxilla during the growth

\begin{tabular}{|l|l|}
\hline \multicolumn{2}{|c|}{ Access this article online } \\
\hline Quick Response Code: \\
\hline
\end{tabular}

period, but about $25 \%$ of these patients do not favorably respond to this treatment and need later surgical interventions. ${ }^{[2,3]}$

This is an open access journal, and articles are distributed under the terms of the Creative Commons Attribution-NonCommercial-ShareAlike 4.0 License, which allows others to remix, tweak, and build upon the work non-commercially, as long as appropriate credit is given and the new creations are licensed under the identical terms.

For reprints contact: reprints@medknow.com

How to cite this article: Tahmasbi S, Jamilian A, Showkatbakhsh $R$, Pourdanesh F, Behnaz M. Cephalometric changes in nasopharyngeal area after anterior maxillary segmental distraction versus Le Fort I osteotomy in patients with cleft lip and palate. Eur J Dent 2018;12:393-7. DOI: 10.4103/ejd.ejd_374_17 
Total maxillary advancement could be accomplished instantly by conventional orthognathic surgery or gradually through distraction osteogenesis (DO). ${ }^{[1]}$ Le Fort I osteotomy offers some advantages over DO method including more predictable and precise results, less office time, and less need to patient cooperation but has some disadvantages such as longer surgery time and relapse tendency specially in CLP patients. ${ }^{[4]}$ It is usually difficult to achieve $>6 \mathrm{~mm}$ maxillary advancement in these patients and about $20 \%-25 \%$ relapse is reported after conventional surgery mostly as a result of previous scars. ${ }^{[5]}$

Forward movement of the soft palate following the anterior repositioning of the entire maxilla may have an adverse effect on the velopharyngeal function (VPF) which is the most important factor influencing the speech in CLP patients. ${ }^{[6,7]}$ There is controversy over this effect in the literature. ${ }^{[8]}$ While some studies have reported no effect on velopharyngeal status and speech after maxillary advancement, others claimed deterioration of VF and triggering or worsening of speech problems in these patients. ${ }^{[9-11]}$ Taha and Elsheikh found a positive correlation between the amount of maxillary advancement by DO and the increase in hypernasality and nasopharyngeal depth. ${ }^{[6]}$ The results of another study ${ }^{[12]}$ showed that the hypernasality is not always proportional to the extent of advancement, but it depends on the posterior pharyngeal wall position and rotation of the palatal plane.

Entire maxillary advancement through conventional Le Fort I osteotomy or DO could be replaced by anterior maxillary segmental distraction (AMSD) in CLP patients to maintain the velopharyngeal area intact. ${ }^{[13]}$

Block and Brister reported the first successful clinical application of AMSD in dogs ${ }^{[14]}$ followed by the experience of Dolanmaz on humans in $2003^{[15]}$ Various studies have been launched on the optimal protocols and ideal patients for AMSD. ${ }^{[2,13,16-19]}$

The presentstudy aimed at evaluating the cephalometric changes of velopharyngeal area following AMSD and comparing them with conventional maxillary advancement in CLP patients. To the best of our knowledge, no other study has been performed such evaluation.

\section{MATERIALS AND METHODS}

This study was approved by the Ethics Committee of Shahid Beheshti University of Medical Sciences in Iran (code IR.SBMU.RIDS.REC.1394.12). This retrospective study was conducted on 20 CLP patients who had surgery for correction of maxillary deficiency and orthodontic treatment. All patients had severe maxillary hypoplasia (SNA < 76) and negative overjet (at least $-4 \mathrm{~mm}$ ). All patients were treated in Dental School of Shahid Beheshti University and their surgeries were performed in Taleghani hospital. According to the surgery method, the patients were divided into two groups of 10 . The first group had classic Le Fort I maxillary advancement and the second group had AMSD with an intraoral tooth-borne distractor (without downfracture).

In the first group, after preoperative orthodontic treatment, routine maxillary advancement was done and followed by postoperative orthodontics (Group A). For the other group (Group B), preoperative orthodontic treatment created a space of about $2 \mathrm{~mm}$ between the maxillary first and second molars. Then, during the surgery, anterior maxillary segmental osteotomy was performed anterior to the second molars with an extra vertical cut between first and second molars. A tooth-borne anteroposterior distractor (a hyrax appliance with $90^{\circ}$ rotation), ${ }^{[20]}$ which was made in advance on a plaster model, was cemented in place in operation room [Figure 1]. One week after the surgery, activation of hyrax screw was started with the rate of 2 times a day for about 10 days until at least edge-to-edge incisal relation was achieved. Afterward, distractor was remained in place for about 4 months. The interdental space created by distraction at the osteotomy site was utilized to correct dental crowding orthodontically, without the need for tooth extraction. A functionally stable occlusion with the alignment of teeth in the arch and a positive overjet were established at the end of 1-year postsurgery in all patients. Final records were prepared approximately 12 months postsurgery.

All initial and final lateral cephalograms were traced and analyzed by OrthoSurgerX software, ${ }^{[21]}$ which was prepared for airway evaluation according

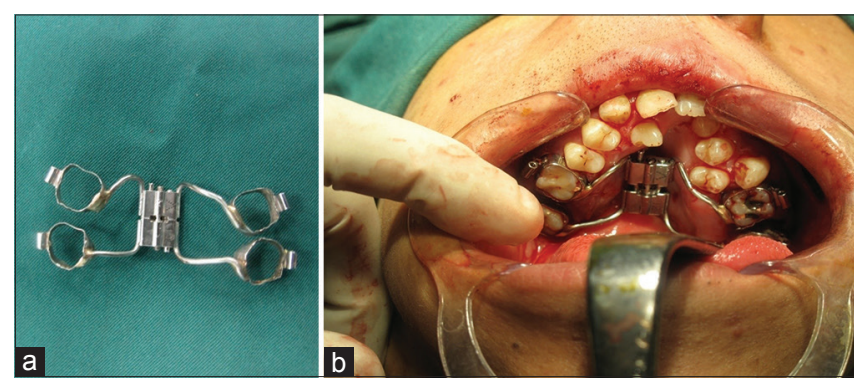

Figure 1: (a and b) Hyrax appliance with $90^{\circ}$ rotation for anterior maxillary segmental distraction 
to Linder-Aronson and Henrikson, ${ }^{[22]}$ Tobias, ${ }^{[23]}$ and Bergland ${ }^{[24]}$ studies. Reference points were marked, yielding 22 linear and seven angular measurements [Figures 2-5]. Linear measurements were adjusted according to SN.

Soft-tissue convexity angle was obtained by Dolphin software (version 10.5, Canoga Park, CA).

\section{Statistical analysis}

Data were analyzed using the SPSS software (SPSS version 22.0, SPSS, Chicago, IL, USA). Among all measurements, the changes in nasopharyngeal area as the most important variable for airway evaluation and also palatal length, nasopharynx floor length, and total maxillary length as linear measurements were analyzed in both groups [Figure 2]. For detecting the amount of maxillary advancement following the surgery, SNA as angular measurement was assessed. Descriptive statistics were calculated in the form of mean and standard deviation. As all variables' distribution was normal, the significance of difference was tested using the repeated measurement ANOVA, considering $\alpha=0.05$ and $\beta=0.2$.

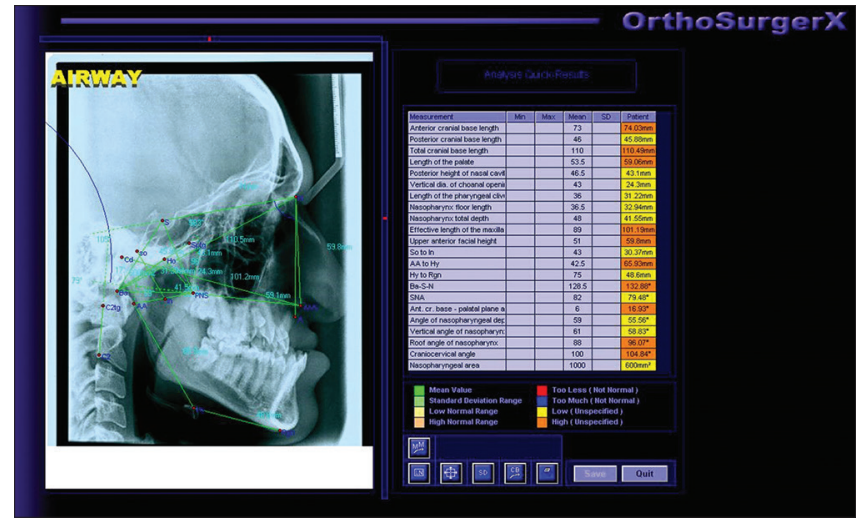

Figure 2: Reference points, 22 linear and seven angular measurements in OrthoSurgerX software

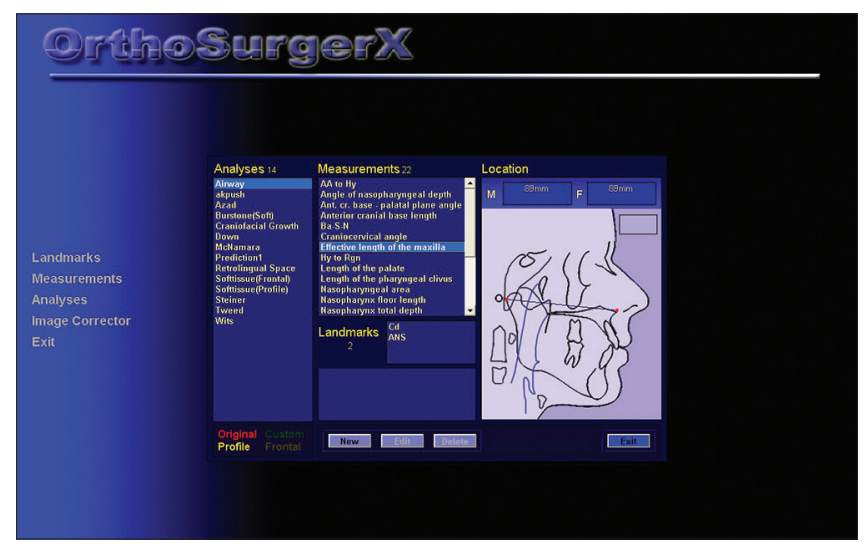

Figure 4: Effective length of the maxilla

\section{RESULTS}

The two groups were matched according to age, sex, severity of maxillary deficiency, and type of CLP. The mean age in Group A and B was 19.3 and 20.5 years, respectively. In Group A, there were 7 men and 3 women, and in Group B, there were 6 men and 4 women. Furthermore, in the first group, there were 8 patients with bilateral CLP and 2 patients with unilateral CLP, while these amounts were 9 and 1 in the second group.

Pretreatment and posttreatment mean cephalometric and $P$ values are presented in Table 1 . Pretreatment values for SNA, overjet, and soft-tissue convexity in Group A were $72.06^{\circ},-5.42 \mathrm{~mm}$, and $178.2^{\circ}$, respectively, while these amounts in Group B were $69.66^{\circ},-5.97 \mathrm{~mm}$, and $176.69^{\circ}$.

In Group A, the changes in nasopharyngeal area, nasopharynx floor length, effective length of maxilla, and SNA were significant, comparing pre- and postsurgery. Following AMSD in Group B, nasopharyngeal area, length of palate, and SNA changed significantly. The changes in all variables

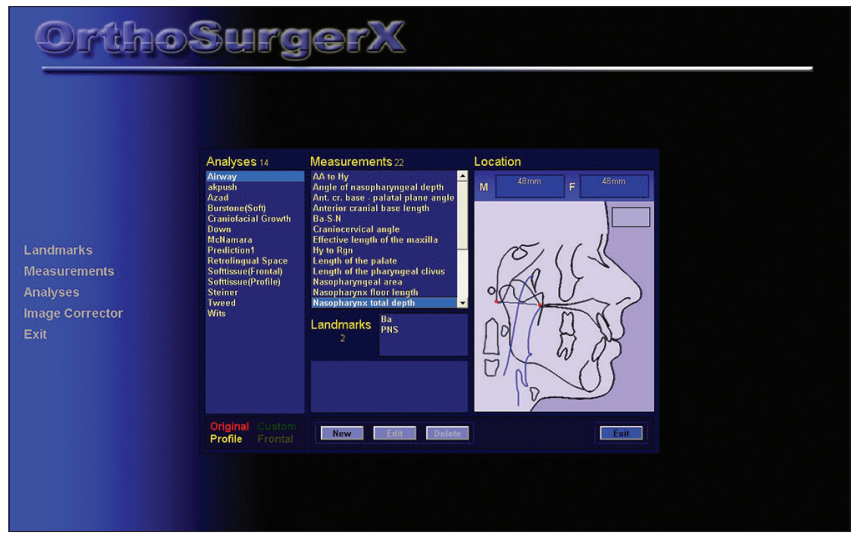

Figure 3: Nasopharynx total depth

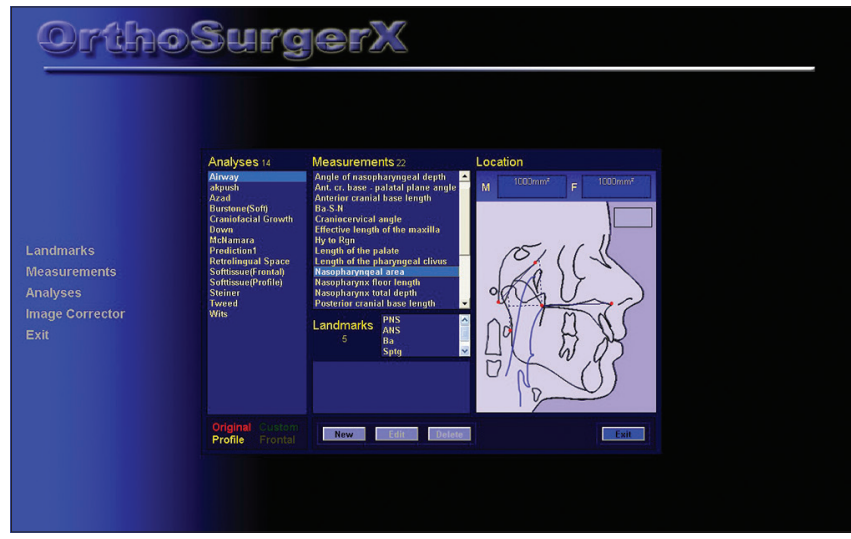

Figure 5: Nasopharyngeal area 
Tahmasbi, et al.: Nasopharyngeal area cephalometric changes in cleft patients

\begin{tabular}{|c|c|c|c|c|c|c|c|}
\hline & \multicolumn{2}{|c|}{ Group A (conventional) } & \multirow{2}{*}{$\begin{array}{l}P \text { value (for changes } \\
\text { in Group A) }\end{array}$} & \multicolumn{2}{|c|}{ Group B (DO) } & \multirow{2}{*}{$\begin{array}{l}P \text { value (for changes } \\
\text { in Group B) }\end{array}$} & \multirow{2}{*}{$\begin{array}{c}P \text { value (between } \\
\text { groups) }\end{array}$} \\
\hline & Pre & Post & & Pre & Post & & \\
\hline Nasopharyngeal area & 628.7 & 818.94 & $0.001^{*}$ & 708.2 & 581.8 & $0.014^{*}$ & $0.000^{*}$ \\
\hline Length of palate & 49.42 & 49.29 & 0.853 & 48.75 & 51.05 & $0.004^{*}$ & $0.023^{*}$ \\
\hline Nasopharynx floor length & 31.6 & 35.47 & $0.004^{*}$ & 32.03 & 29.99 & 0.097 & $0.002^{*}$ \\
\hline Nasopharynx total depth & 42.36 & 45.07 & 0.081 & 42.90 & 41.17 & 0.255 & $0.046^{*}$ \\
\hline Effective length of maxilla & 85.56 & 90.41 & $0.001^{*}$ & 86.45 & 87.64 & 0.319 & $0.038^{*}$ \\
\hline SNA & 72.06 & 77.94 & $0.000^{*}$ & 69.66 & 72.89 & $0.004^{*}$ & 0.073 \\
\hline Overjet & -5.42 & 1.14 & $0.000^{*}$ & -5.97 & 1.88 & $0.000^{*}$ & 0.953 \\
\hline Soft tissue convexity & 178.2 & 167.9 & $0.000^{*}$ & 176.69 & 170.32 & $0.001^{*}$ & 0.552 \\
\hline
\end{tabular}

evaluating velopharyngeal status demonstrated in Table 1 showed a significant difference between the two groups. In Group A (conventional method), the mean of nasopharyngeal area pre- and post-treatment was $628.7 \mathrm{~mm}^{2}$ and $818.94 \mathrm{~mm}^{2}$, respectively, which shows significant increase $(P<0.05)$ after the surgery, while in Group B (DO method), the trend of changes was vice versa and these amounts were $708.2 \mathrm{~mm}^{2}$ (before surgery) and $581.8 \mathrm{~mm}^{2}$ (after surgery) indicating significant decrease $(P<0.05)$ following the distraction.

Another important variable is SNA which indicates these methods' success in maxillary advancement. Following conventional advancement in Group A, the SNA mean changed from $72.06^{\circ}$ to $77.94^{\circ}(P<0.05)$, whereas DO method in Group B changed the mean SNA from $69.66^{\circ}$ presurgery to $72.89^{\circ}$ postsurgery $(P<0.05)$. Comparison between the two groups showed no significant difference $(P=0.073)$. The changes in overjet and soft-tissue convexity were also similar in both groups $(P=0.953$ and $P=0.552$, respectively).

\section{DISCUSSION}

Changes in speech and velopharyngeal function (VPF) after maxillary advancement through conventional Le Fort I or even distraction of total maxillae have been reported in CLP patients. ${ }^{[9-11,25]}$ AMSD has been proposed to advance the anterior segment of the maxillae and create the space in maxillary arch without deterioration of the velopharyngeal function. Patients with anterior crossbite, concave profile due to maxillary deficiency, crowding or tooth impaction in the upper arch, and velopharyngeal insufficiency are good candidates for this technique. ${ }^{[13,19,26]}$

In the present study, we compared the effect of AMSD and conventional maxillary advancement on changes in cephalometric variables evaluating the amount of advancement and velopharyngeal status which was performed in no previous study. Various appliances including external and internal distractors such as the Dynaform system, modified hyrax appliance, and the hybrid distractors have been reported to be used for anterior maxillary distraction. ${ }^{[27,28]}$ The modified hyrax appliance, which was used as the distractor in this study, had the advantage of easy fabrication, minimal expense, and good patient tolerance.

In both groups, analysis of the sagittal position of the maxilla through SNA, soft-tissue convexity, and overjet showed significant changes, which were expected as a result of distraction or surgical advancement, while these changes had no significant difference between the two groups. This fact shows that the amount of A point advancement was almost the same in both groups. Other studies also showed significant facial profile improvement following AMSD. ${ }^{[2,13,17]}$

When the maxilla was brought forward by conventional advancement, the nasopharyngeal area was increased significantly, which shows that velopharyngeal function probably has been adversely affected. This effect has been reported in previous studies following Le Fort I osteotomy ${ }^{[29,30]}$ or even after maxillary advancement by distraction. ${ }^{[6,12,31]}$ They found a significant positive correlation between the amount of forward skeletal movement and postdistraction hypernasality and pharyngeal depth. ${ }^{[6,31]}$ Chua et al. concluded that total maxillary distraction has no advantage over conventional advancement for the purpose of preventing velopharyngeal incompetence and speech disturbance in moderate cleft maxillary advancement. ${ }^{[9]}$ On the contrary, in the AMSD group, the nasopharyngeal area was decreased significantly and nasopharynx floor length also showed an insignificant decrease, which are favorable changes in the velopharyngeal sphincter. Furthermore, length 
of palate was increased significantly in AMSD group, while it had no change in conventional method, as expected.

This proposes no detrimental effect on speech. To the best of our knowledge, just one study by Rao Janardhan et al. had been evaluated the effect of AMSD on speech, and they found no deterioration of speech after AMSD. ${ }^{[2]}$

\section{CONCLUSION}

AMSD of the hypoplastic cleft maxilla can improve facial balance and esthetics, almost similar to the conventional Le Fort I advancement, while there is a significant decrease in nasopharyngeal; hereby, there is no increase in the velopharyngeal sphincter.

\section{Financial support and sponsorship}

Nil.

\section{Conflicts of interest}

There are no conflicts of interest.

\section{REFERENCES}

1. Cheung LK, Chua HD. A meta-analysis of cleft maxillary osteotomy and distraction osteogenesis. Int J Oral Maxillofac Surg 2006;35:14-24.

2. Rao Janardhan S, Kotrashetti SM, Lingaraj JB, Pinto PX, Keluskar KM, Jain $\mathrm{S}$, et al. Anterior segmental distraction osteogenesis in the hypoplastic cleft maxilla: Report of five cases. Sultan Qaboos Univ Med J 2013;13:454-9.

3. Ross RB. Treatment variables affecting facial growth in complete unilateral cleft lip and palate. Cleft Palate J 1987;24:5-77.

4. Van Sickels JE. Distraction osteogenesis versus orthognathic surgery. Am J Orthod Dentofacial Orthop 2000;118:482-4.

5. Gateno J, Engel ER, Teichgraeber JF, Yamaji KE, Xia JJ. A new le fort I internal distraction device in the treatment of severe maxillary hypoplasia. J Oral Maxillofac Surg 2005;63:148-54.

6. Taha M, Elsheikh YM. Velopharyngeal changes after maxillary distraction in cleft patients using a rigid external distraction device: A retrospective study. Angle Orthod 2016;86:962-8.

7. Maegawa J, Sells RK, David DJ. Pharyngoplasty in patients with cleft lip and palate after maxillary advancement. J Craniofac Surg 1998;9:330-5.

8. Chanchareonsook N, Samman N, Whitehill TL. The effect of cranio-maxillofacial osteotomies and distraction osteogenesis on speech and velopharyngeal status: A critical review. Cleft Palate Craniofac J 2006;43:477-87.

9. Chua HD, Whitehill TL, Samman N, Cheung LK. Maxillary distraction versus orthognathic surgery in cleft lip and palate patients: Effects on speech and velopharyngeal function. Int J Oral Maxillofac Surg 2010;39:633-40.

10. Trindade IE, Yamashita RP, Suguimoto RM, Mazzottini R, Trindade AS Jr. Effects of orthognathic surgery on speech and breathing of subjects with cleft lip and palate: Acoustic and aerodynamic assessment. Cleft Palate Craniofac J 2003;40:54-64.
11. Witzel MA, Munro IR. Velopharyngeal insufficiency after maxillary advancement. Cleft Palate J 1977;14:176-80.

12. Satoh K, Nagata J, Shomura K, Wada T, Tachimura T, Fukuda J, et al. Morphological evaluation of changes in velopharyngeal function following maxillary distraction in patients with repaired cleft palate during mixed dentition. Cleft Palate Craniofac J 2004;41:355-63.

13. Bengi O, Karaçay S, Akin E, Okçu KM, Olmez H, Mermut S, et al. Cephalometric evaluation of patients treated by maxillary anterior segmental distraction: A preliminary report. J Craniomaxillofac Surg 2007;35:302-10.

14. Block MS, Brister GD. Use of distraction osteogenesis for maxillary advancement: Preliminary results. J Oral Maxillofac Surg 1994;52:282-6.

15. Dolanmaz D, Karaman AI, Ozyesil AG. Maxillary anterior segmental advancement by using distraction osteogenesis: A case report. Angle Orthod 2003;73:201-5.

16. Gunaseelan R, Cheung LK, Krishnaswamy R, Veerabahu M. Anterior maxillary distraction by tooth-borne palatal distractor. J Oral Maxillofac Surg 2007;65:1044-9.

17. Alkan A, Baş B, Ozer M, Bayram M, Yüzbasioğlu E. Maxillary anterior segmental advancement of hypoplastic maxilla in cleft patients by distraction osteogenesis: Report of 2 cases. J Oral Maxillofac Surg 2008;66:126-32.

18. Gualini C. Advancement of maxillary anterior segment by distraction osteogenesis (DO): A case report. Prog Orthod 2007;8:54-61.

19. Wang XX, Wang $X$, Li ZL, Yi B, Liang C, Jia YL, et al. Anterior maxillary segmental distraction for correction of maxillary hypoplasia and dental crowding in cleft palate patients: A preliminary report. Int J Oral Maxillofac Surg 2009;38:1237-43.

20. Showkatbakhsh R, Pourdanesh F, Jamilian A, Ghorbani A, Behnaz M. Hyrax application as a tooth-borne distractor for maxillary advancement. J Craniofac Surg 2011;22:1361-6.

21. Nouri M, Alijani S, Akbarzade A. Changes in craniofacial morphology, head and neck posture following mandibular setback surgery. Iran J Orthod 2013;8:47-56.

22. Linder-Aronson S, Henrikson CO. Radiocephalometric analysis of anteroposterior nasopharyngeal dimensions in 6-to 12-year-old mouth breathers compared with nose breathers. ORL J Otorhinolaryngol Relat Spec 1973;35:19-29.

23. Tobias PV. The nasopharynx: Review of structure and development, with notes on speech, pharyngeal hypophysis, chordoma and the dens. J Dent Assoc S Afr 1981;36:765-78.

24. Bergland $\mathrm{O}$. The bony nasopharynx. A roentgen-craniometric study. Acta Odontol Scand 1963;21 Suppl 35:1-137.

25. Guyette TW, Polley JW, Figueroa A, Smith BE. Changes in speech following maxillary distraction osteogenesis. Cleft Palate Craniofac J 2001;38:199-205.

26. Okcu KM, Sencimen M, Karacay S, Bengi AO, Ors F, Dogan N, et al. Anterior segmental distraction of the hypoplastic maxilla by a tooth borne device: A study on the movement of the segment. Int J Oral Maxillofac Surg 2009;38:817-22.

27. Karakasis D, Hadjipetrou L. Advancement of the anterior maxilla by distraction (case report). J Craniomaxillofac Surg 2004;32:150-4.

28. Aikawa T, Haraguchi S, Tanaka S, Uematsu S, Ishibashi M, Kogo M, et al. Rotational movement of the anterior maxillary segment by hybrid distractor in patients with cleft lip and palate. Oral Surg Oral Med Oral Pathol Oral Radiol Endod 2010;110:292-300.

29. Kummer AW, Strife JL, Grau WH, Creaghead NA, Lee L. The effects of le fort I osteotomy with maxillary movement on articulation, resonance, and velopharyngeal function. Cleft Palate J 1989;26:193-9.

30. Schendel SA, Oeschlaeger M, Wolford LM, Epker BN. Velopharyngeal anatomy and maxillary advancement. J Maxillofac Surg 1979;7:116-24.

31. Ko EW, Figueroa AA, Guyette TW, Polley JW, Law WR. Velopharyngeal changes after maxillary advancement in cleft patients with distraction osteogenesis using a rigid external distraction device: A 1-year cephalometric follow-up. J Craniofac Surg 1999;10:312-20. 